\title{
Evaluation of an Australian health literacy training program for socially disadvantaged adults attending basic education classes: study protocol for a cluster randomised controlled trial
}

\author{
Kirsten J. McCaffery ${ }^{1,2^{*}}$, Suzanne Morony ${ }^{1,2}$, Danielle M. Muscat ${ }^{1,2}$, Sian K. Smith ${ }^{3}$, Heather L. Shepherd ${ }^{2,4}$,
} Haryana M. Dhillon ${ }^{5,6}$, Andrew Hayen ${ }^{7}$, Karen Luxford ${ }^{8}$, Wedyan Meshreky ${ }^{9}$, John Comings ${ }^{10}$ and Don Nutbeam ${ }^{1}$

\begin{abstract}
Background: People with low literacy and low health literacy have poorer health outcomes. Literacy and health literacy are distinct but overlapping constructs that impact wellbeing. Interventions that target both could improve health outcomes.

Methods/design: This is a cluster randomised controlled trial with a qualitative component. Participants are 300 adults enrolled in basic language, literacy and numeracy programs at adult education colleges across New South Wales, Australia. Each adult education institute (regional administrative centre) contributes (at least) two classes matched for student demographics, which may be at the same or different campuses. Classes (clusters) are randomly allocated to receive either the health literacy intervention (an 18-week program with health knowledge and skills embedded in language, literacy, and numeracy training (LLN)), or the standard Language Literacy and Numeracy (LLN) program (usual LLN classes, specifically excluding health content).

The primary outcome is functional health literacy skills - knowing how to use a thermometer, and read and interpret food and medicine labels. The secondary outcomes are self-reported confidence, more advanced health literacy skills; shared decision making skills, patient activation, health knowledge and self-reported health behaviour. Data is collected at baseline, and immediately and 6 months post intervention. A sample of participating teachers, students, and community health workers will be interviewed in-depth about their experiences with the program to better understand implementation issues and to strengthen the potential for scaling up the program.
\end{abstract}

Discussion: Outcomes will provide evidence regarding real-world implementation of a health literacy training program with health worker involvement in an Australian adult education setting. The evaluation trial will provide insight into translating and scaling up health literacy education for vulnerable populations with low literacy.

Trial registration: Australian New Zealand Clinical Trials Registry ACTRN12616000213448.

Keywords: Literacy, Health literacy, Adult education, Shared decision making, Numeracy, Health disparities, Minority health, Underserved patients, Social inequality, Social disadvantage

\footnotetext{
* Correspondence: kirsten.mccaffery@sydney.edu.au

'Sydney School of Public Health, The University of Sydney, Sydney, NSW 2006, Australia

${ }^{2}$ Centre for Medical Psychology and Evidence-based Decision-making

(CeMPED), Sydney School of Public Health, The University of Sydney, Sydney,

NSW 2006, Australia

Full list of author information is available at the end of the article
}

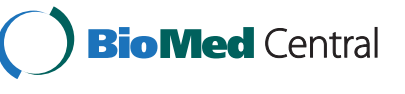

(c) 2016 McCaffery et al. Open Access This article is distributed under the terms of the Creative Commons Attribution 4.0 International License (http://creativecommons.org/licenses/by/4.0/), which permits unrestricted use, distribution, and reproduction in any medium, provided you give appropriate credit to the original author(s) and the source, provide a link to the Creative Commons license, and indicate if changes were made. The Creative Commons Public Domain Dedication waiver (http://creativecommons.org/publicdomain/zero/1.0/) applies to the data made available in this article, unless otherwise stated. 


\section{Background}

\section{Low literacy and health literacy}

Health literacy is commonly defined as the capacity to acquire, understand and use information in ways which promote and maintain good health [1, 2]. As with general literacy, health literacy skills can be described and measured at different levels: "functional" (the health skills required to function in everyday situations), "communicative/interactive" (more advanced skills to extract information, discriminate between different sources of information and derive meaning) and "critical" (the ability to critically analyse information) $[3,4]$. Health literacy involves the capacity to use health information, not simply to obtain it [3].

To the extent that health literacy involves engaging with written information, it is strongly influenced by language, literacy and numeracy (LLN); hence some commonly used measures of health literacy (e.g. REALM [5], TOFHLA [6]) measure recognition and use of health vocabulary. Individuals with limited literacy skills are less likely to engage in preventative healthcare, are more likely to develop chronic illnesses [7] and, once developed, experience greater difficulties managing those illnesses and often die earlier [8]. In Australia, up to $60 \%$ of adults lack basic health literacy skills to understand healthrelated materials, such as instructions on a medicine label [9]. Estimates of low health literacy in Europe (47\%) [10] and the US (36 \%) [11] are similarly high. Building health literacy is a priority in Australia and internationally [10, 12-14].

Closely aligned with emerging interest in population heath literacy has been a growing recognition of the value of Shared Decision Making in health care. Shared Decision Making occurs when patients and health professionals work together to jointly make decisions about a patient's health $[15,16]$. It is a cornerstone of high quality healthcare and now endorsed by major health organisations internationally $[13,17,18]$. Research shows that patients who share health decisions have higher health knowledge, more accurate risk perceptions, reduced difficulty with decisionmaking $[19,20]$, and in some circumstances show improved clinical outcomes [21-23]. Shared Decision Making and involvement in health care generally may be viewed within Nutbeam's conceptual framework as "communicative" and "critical" health literacy. Yet there has been relatively little effort to support Shared Decision Making for adults with low general literacy and it has not been incorporated into health literacy programs to date [24]. There is a need to both develop and test health literacy interventions that support Shared Decision Making for adults with lower levels of general literacy.

\section{Health literacy interventions}

Partnerships between health and education agencies offer promise in building health literacy in the population [25], especially if they collaborate to access hard-toreach groups and develop strategies to improve both health literacy, and general language, literacy, and numeracy (LLN) skills [26, 27]. The field of adult literacy has been cautious about integrating health content into adult education programs due to concerns that teachers may lack the expertise and confidence to deliver topics about health [28]. This is changing, although rigorous evaluations are lacking.

In the US, the Health Literacy Study Circles is a program providing teachers tools to develop health-related units, lessons and action plans [29]. The program as part of a broader intervention has been reported to increase students' health-related knowledge and selfefficacy [30]. Three 'health literacy' style programs have been run in adult education settings and evaluated in randomised trials in the US [31-33]. Although published work has indicated some degree of success of these programs [32], only one was published in a peer reviewed journal [33] making it difficult to ascertain how effective these programs have been. The one published study, a trial of a community-based health literacy/English as a Second Language program was targeted at Hispanics in the United States. It showed promising increases in health-related verbal fluency (using the TOFHLA) in the health literacy arm [33] immediately post intervention but there was no further follow up and measures focused on a functional health literacy only.

A UK based program that embedded health content into adult basic education was the Skilled for Health program [34]. It found that health content helped to engage and retain socially disadvantaged adult learners and participants reported improved understanding about health and healthier behaviours (diet, exercise and smoking). However, improvements in specific health literacy skills were not directly assessed and health literacy and health behaviour outcomes were measured by self-report. Additionally the study did not use a randomised design and lacked a control group for rigorous comparison [34].

\section{The Australian health literacy program}

We aim to evaluate the efficacy of an intervention similar to Skilled for Health, adapted for an Australian context using a randomised trial design, with outcomes assessed immediately post intervention and at 6 months to determine whether any health literacy gains are retained.

A novel addition to the program in this study is the development and inclusion of a Shared Decision 
Making component (see [35]). This seeks to teach students about the concept of Shared Decision Making (i.e. teaching them that there are often different test and treatment options, that they have a choice between options, and that they have the right to ask questions); provide education about probability and risk, (i.e. how to understand the outcomes and likelihood of different options); and develop self-efficacy to express preferences and be actively involved in health decisions. Specifically, we introduced the AskShareKnow questions [36] to students (What are my options? What are the possible benefits and harms of those options? How likely are each of those benefits and harms to happen to me?) as a generic Shared Decision Making tool to help achieve these aims. The AskShareKnow questions have been shown to increase the amount and quality of information about treatment options provided by family physicians and increase Shared Decision Making behaviours in consultations [36], and the demonstration of these questions via a short video clip in a clinic waiting room was found to be a feasible approach to increase question asking in health care consultations [37].

The population of adults attending basic LLN classes in Australia comprises two distinct groups: native English speakers (mostly Australian-born) who may have experienced a range of learning disabilities, did not complete school, or are retraining as a condition of their unemployment benefits; and (migrants) from culturally and linguistically diverse backgrounds (CALD) who may fit any or none of the above conditions. Some of these migrants are highly-educated, but have poor (oral and/or written) English skills; others may have never attended school. The challenge is to develop a program flexible enough to cater to the different needs of these populations and deliver measureable differences in health literacy outcomes.

\section{Study objectives}

This is a cluster randomised controlled trial that aims to evaluate a best practice model to:

a) Deliver improvements in health literacy, confidence in health skills, Shared Decision Making, and knowledge about health and healthy behaviour, through a health literacy education program.

b) Demonstrate improved engagement in learning (through higher attendance at classes) and greater enrolment in further adult education classes.

c) Assess feasibility for delivery in a variety of locations (metropolitan, regional, and remote).

The health literacy program will be compared to a standard adult language, literacy and numeracy (LLN) program which would be expected to achieve some improvements which extend to health literacy outcomes also. Therefore this trial will examine the added benefit the health literacy program brings to health literacy related outcomes.

\section{Methods \\ Study design}

This study is a matched cluster randomised controlled trial (Fig. 1), in which a class represents a cluster. Each participating institute will be required to provide (at least) one matched pair of classes, in which a pair comprises one intervention and one standard LLN class. The two classes within each pair will be a priori matched for typical student demographics (e.g. day or evening students; metropolitan or regional; predominance of native English or NESB students) and enrolled in the same course code.

Intervention and standard LLN classes will have the same TAFE-specified units of competency to cover. Students in the health literacy ("intervention") classes will learn literacy and numeracy skills with content focused on health topics; the standard LLN classes will cover the same literacy and numeracy skills, in contexts other than health. These "standard LLN" classes control for both expected literacy gains as well as any research participation effects [38].

\section{Ethics and dissemination}

The study has ethical approval from the University of Sydney Human Research Ethics Committee and 10 NSW Institutes of TAFE. Results will be published in peer reviewed journals, and reported to partner organisations. Written informed consent will be obtained from all participants.

\section{Recruitment}

Students and teachers will be recruited from TAFE institutes in NSW, Australia. There are 10 Institutes of TAFE in NSW - each one will be invited to join the study for a full (18-week) semester, and to contribute at least one matched pair of classes delivering the same TAFE course (in the same or different location).

All students enrolled in each participating class will be invited to participate in the study during the first class. To assist recruitment, the researchers (KM, SM, DM) created a video introducing themselves and explaining the purpose of the study.

Participating classes will be basic LLN courses corresponding to Level 2 (basic/beginner) of the 5-level Australian Core Skills Framework (ACSF). The ACSF describes performance on the 5 skills of learning, reading, writing, oral communication, and numeracy, and is assessed by TAFE teachers at student 


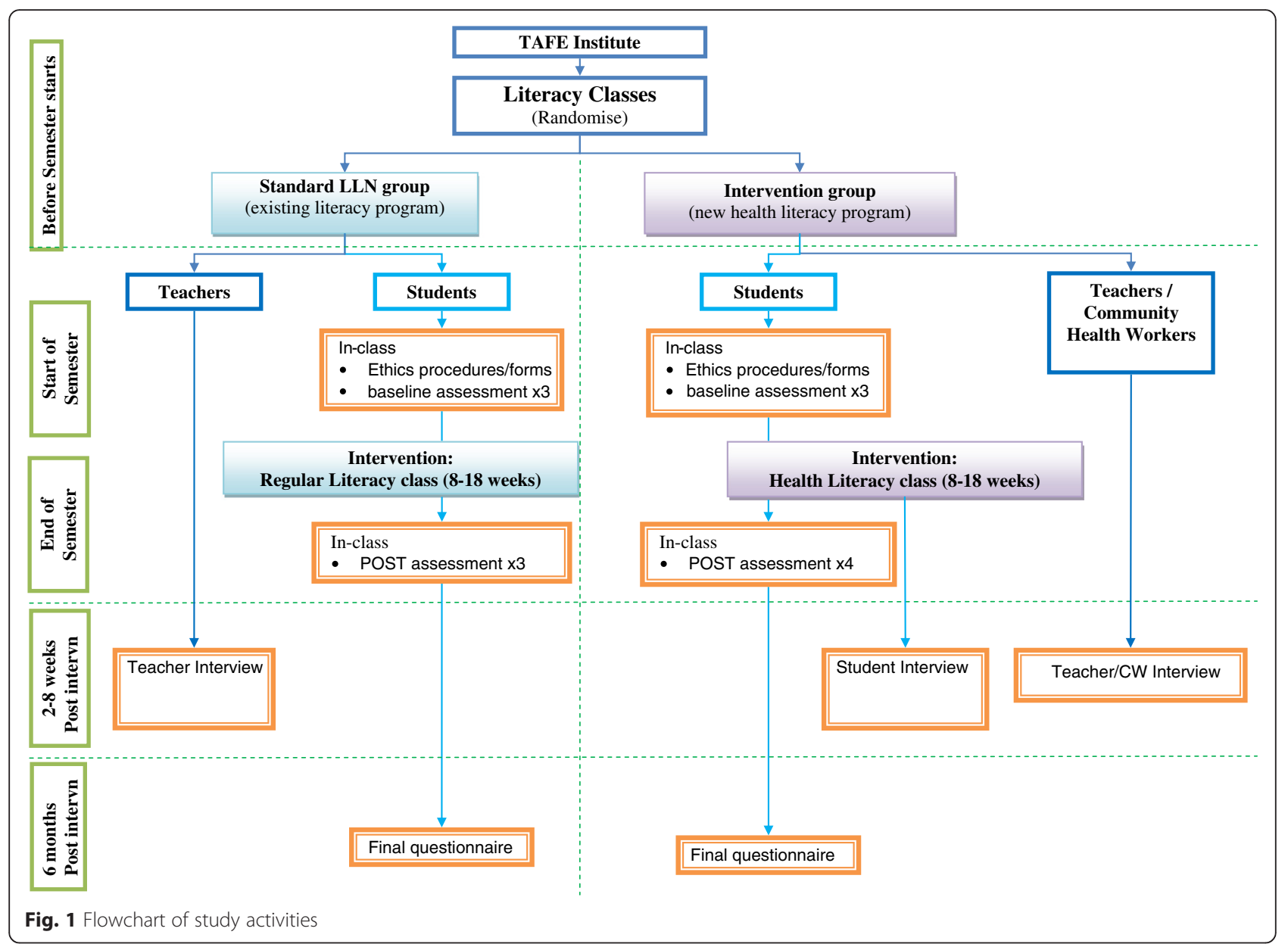

enrolment. Each TAFE course has a designated code, and specifies LLN learning outcomes that students must achieve. For relevant course codes, a "mapping" document produced by a TAFE coordinator indicates which units of the health literacy program cover each LLN competency.

\section{Randomisation}

At enrolment, students will be allocated to classes following normal TAFE procedures. Classes will be randomised centrally into "intervention" or "standard LLN" groups by the University of Sydney team. At campuses holding only one class participating in the study, all enrolling students will be allocated to that class. At larger metropolitan campuses with more than one participating class, students will be randomised into classes on enrolment day, by selecting an "odd" or "even" paper ticket. Matched classes at the same location will be held on different days to minimise risk of contamination between intervention and standard groups.

\section{Participants and setting}

Participants will be recruited following standard TAFE processes for enrolling students. Participating TAFE teachers will invite 300 adults assessed at ACSF level 2, seeking basic education at TAFE in NSW to join the study. As part of standard procedures, students' literacy and numeracy levels are assessed by TAFE teachers on enrolment day.

\section{Participating sites}

We will recruit classes from TAFE Institutes in metropolitan and regional centres across NSW, Australia, including multiple Sydney districts, and Illawarra, Hunter, New England, and Southern NSW.

\section{Inclusion criteria}

Eligible classes will be learning basic language, literacy and numeracy at ACSF level 2 (in one of 4 eligible course codes). Intervention and standard LLN classes will be matched on typical demographic characteristics including age, sex, English proficiency, literacy skills, course code, and region. Students will be 16 years and older. Consent from a parent or guardian must be obtained for students under 18 years. 


\section{Intervention: the health literacy program}

Australian adult education and public health experts adapted the UK Skilled for Health program to an Australian context. The revised program embeds key LLN skills development at the Australian Core Skills Framework level 2 into materials containing healthrelated topics focused on public health priorities (as identified by NSW Health) using Functional Context Education (FCE) methods [39]. In this approach students learn specified LLN skills through engaging with health material guided by their teacher [40]. We added a Shared Decision-Making program centred around the AskShareKnow questions (as described in [35]) that teaches participants about participating in decision making about their health, using recommended questions to elicit information from healthcare professionals, and discussing how to understand their responses.

The program consists of two teaching manuals:

(1) "Being Healthy", which covers health skills such as using a thermometer, understanding prescriptions, communicating with health professionals, and Shared Decision-Making; and

(2) "Staying Healthy", which focuses on diet and exercise (healthy lifestyle).

The 16 Being Healthy and 14 Staying Healthy topics are listed in Table 1. Teachers will be given a suggested delivery plan, with advice that they may diverge from

Table 1 Course content

\begin{tabular}{|c|c|}
\hline $\begin{array}{l}\text { Being healthy } \\
\text { Teacher manual } 1\end{array}$ & $\begin{array}{l}\text { Staying healthy } \\
\text { Teacher manual } 2\end{array}$ \\
\hline 1.1 Taking temperature ${ }^{a}$ & 2.1 Getting involved \\
\hline 1.2 Checking medicine labels ${ }^{a}$ & 2.2 Food groups \\
\hline 1.3 Prescriptions & 2.3 Food labels ${ }^{a}$ \\
\hline 1.4 Dosage and timing & 2.4 Nutritional information ${ }^{a}$ \\
\hline 1.5 Health workers & 2.5 Food temperature safety \\
\hline 1.6 Telling your doctor what is wrong ${ }^{a}$ & 2.6 Food date safety \\
\hline 1.7 Talking to your doctor ${ }^{a}$ & 2.7 What is a serve? ${ }^{a}$ \\
\hline 1.8 Answering your doctor's questions ${ }^{a}$ & 2.8 Budgeting \\
\hline 1.9 Immunisation and health screening & 2.9 Understanding a diet \\
\hline 1.10 Asking questions ${ }^{\mathrm{a}}$ & 2.10 Drinking enough fluids \\
\hline 1.11 Shared decision-making ${ }^{a}$ & 2.11 Heart Rate and Pulse \\
\hline 1.12 Completing medical forms & 2.12 Being Active \\
\hline 1.13 Emergency services & $\begin{array}{l}2.13 \text { Watch First Aid } \\
\text { demonstrations }\end{array}$ \\
\hline 1.14 Advice from pharmacist & 2.14 Follow written instructions \\
\hline 1.15 Saving lives & 2.15 Talking on the telephone \\
\hline 1.16 Follow emergency instructions & Revision/Goal setting \\
\hline
\end{tabular}

${ }^{\mathrm{a} C o r e}$ topic this, according to the interests and capabilities of their students. The main requirement for delivery is that classes cover all 10 "core" topics considered central to the health literacy learning objectives and linked to the quantitative assessments. For the remainder of lessons students and teachers can select topics of most interest and relevance to the class.

Development and piloting of the teacher manuals is described elsewhere [41]. Following the pilot, the program was modified in response to participant feedback; and sent to Australian health experts (including partner organisations NSW Health, NPS Medicine Wise, NSW Clinical Excellence Commission) for review. The final manuals can be obtained from the corresponding author.

\section{LLN (standard LLN) program}

Standard LLN students will complete the "standard" TAFE content for the units of study. This includes learning computer skills, employment skills, and other nonhealth related activities and is designed to develop core skills and confidence in language, and improve functional English language, literacy and numeracy skills.

\section{Sample size}

The primary outcome for sample size calculation is the functional health literacy score used in our pilot study ([41]). We estimate that 86 students are required per group to detect a difference in the mean total score between the intervention and standard LLN groups of 0.5 standard deviation (SD) with $90 \%$ power at the twosided $5 \%$ significance level. An established systematic review indicates that a half-standard deviation is the 'threshold of discrimination', or the minimally important difference, for changes to psychosocial outcomes in chronic disease assessment [42]. To allow for clustering within a class and using an intra-cluster correlation coefficient of 0.05 and an average class size of 10, the required sample size is 125 students. Allowing for $15 \%$ loss to follow-up, we aim to recruit 150 participants in each arm $(n=300$ in total; 15 pairs of classes of approximately 10 students per class). This sample size will also be sufficient to detect a difference in retention of at least $20 \%$ between the intervention and standard LLN group, with $80 \%$ power. Due to the unpredictability of TAFE enrolments, unequal cluster sizes are assumed.

\section{Procedures}

The program will be delivered by adult literacy teachers -with support from community health workers in the health literacy arm to assist with health-related content. All (health literacy and standard LLN) teachers will be trained in study procedures by University of Sydney researchers, and supplied with a study manual outlining rationale, procedures and timelines. Baseline measures will 
be taken on entry into the program and the short-term follow-up assessment will be conducted on completion of the program. Assessments will be split over several teaching sessions to spread student workload and delivered face-to-face by the adult literacy teacher (see Fig. 1). Participants will be invited to a further data-collection session 6 months following course completion, where they will receive $\$ 20$ for their time. Students who are unable to attend the session will be able to complete the questionnaire by phone or mail.

\section{Blinding}

Students will be invited to participate in a research trial but will be blinded as far as possible to its aims. Students will be informed simply that the study is about a new adult literacy program, the "Living Literacy Program", but will not be informed that its purpose is to evaluate a health literacy program. Detail about the purpose of the trial will be given in a debrief statement following the final data collection session (6 months after course conclusion).

\section{Measures}

Outcomes will be evaluated among students and teachers using a mixed methods approach. Table 2 summarises all outcome measures and timing of data collection for the study.

\section{Evaluation among students Quantitative evaluation}

Baseline measures Include demographic and health literacy screening questions. Demographic information includes age, sex, country of birth, language spoken at home, and self-reported health status.

Health literacy includes: the Single Item Literacy Screener (SILS) "How often do you need to have someone help you when you read instructions, pamphlets, or other written material from your doctor or pharmacy?" [43]; self-report of reading ability "How would you rate your ability to read" [44], using a cut off of 3 "sometimes"/"okay" to denote poor literacy; Newest Vital Sign (NVS) [45] with minor modification to the food units

Table 2 Data assessment schedule

\begin{tabular}{|c|c|c|c|c|c|}
\hline & \multirow[t]{2}{*}{ Baseline } & \multicolumn{4}{|c|}{ Post intervention } \\
\hline & & Immed & 2 months & 6 months & $6-12$ months \\
\hline \multicolumn{6}{|l|}{ Quantitative evaluation } \\
\hline Demographics & $x$ & & & $x$ & \\
\hline $\begin{array}{l}\text { Health literacy measures } \\
\text { - Single Item Literacy Screener (SILS) } \\
\text { - Reading ability } \\
\text { - Newest Vital Sign (NVS) }\end{array}$ & $x$ & & & & \\
\hline Health skills & $x$ & $x$ & & & \\
\hline Confidence (in health activities) & $x$ & $x$ & & $x$ & \\
\hline Health Literacy Questionnaire & $x$ & $x$ & & $x$ & \\
\hline Patient Activation Measure & & $x$ & & & \\
\hline Shared Decision Making & & $x$ & & $x$ & \\
\hline Student evaluation & & $x$ & & & \\
\hline $\begin{array}{l}\text { Healthy lifestyle (self-report) } \\
\text { • Fruit and vegetable intake } \\
\text { - Physical activity }\end{array}$ & & & & $x$ & \\
\hline Health knowledge & & & & $x$ & \\
\hline \multicolumn{6}{|l|}{ Qualitative evaluation } \\
\hline Teacher interview - intervention & & & $x$ & & \\
\hline Teacher interview - standard LLN & & & $x$ & & \\
\hline Student interview - intervention & & & $x$ & & \\
\hline Student interview - standard LLN & & & $x$ & & \\
\hline Comm. health worker interview & & & $x$ & & \\
\hline \multicolumn{6}{|l|}{ Education outcomes } \\
\hline LLN outcomes & & $x$ & & & \\
\hline Attendance at classes & & $x$ & & & \\
\hline Enrolment in future TAFE classes & & & & & $x$ \\
\hline
\end{tabular}


presented in the stimulus to make it suitable for use in Australia.

We will take baseline measures of the main primary and secondary outcomes: functional health literacy skills (described below and in Additional file 1), confidence, and components of the Health Literacy Questionnaire (HLQ), described below.

Immediate post intervention outcomes The primary outcome of functional health literacy skill will be assessed using a purpose designed measure informed by the intervention course core content (see Additional file 1):

a) How to use a thermometer (score range 0-3).

b) Interpretation of a medicine labels, (score range 0-5).

c) Interpretation of a food label, 9 items (score range 0-10; not assessed at baseline).

Knowledge scores will be calculated using a marking scheme developed a priori (see Additional file 2). Health skills tasks will be assessed separately, as well as a combined outcome, which will be a weighted sum of the components.

Secondary outcomes will be:

1. Confidence in health skills -10 confidence items modified from [46], measured on a 5-point scale ranging from "extremely" to "not at all" confident. 1. Telling the doctor what is wrong; 2 .

Understanding your doctor; 3. Reading and understanding medicine labels; 4. Filling out medical forms by yourself; 5 . Preventing problems with your health; 6 . Taking care of your family and friends' health; 7. Reading and understanding food labels; 8. Planning healthy meals; 9. Using a thermometer; 10. Asking the doctor questions.

2. The Health Literacy Questionnaire (HLQ) [47] comprises 9 independent subscales to assess different aspects of health literacy. We selected 5 scales relevant to the learning objectives of the study intervention program (Having sufficient information to manage my health; Actively managing my health; Ability to engage with healthcare providers; Navigating the healthcare system; Understanding health information well enough to know what to do) rated on a 4-point scale or 5-point scale (25 items total).

3. The 13-item generic Patient Activation Measure [48] includes self-reported ability of the individual to enact skills of health literacy using items assessing patients' skills and confidence in managing their health.

4. Student satisfaction with the health literacy program. As in [41] we will ask students to rate their course experience using 5-point Likert scale items: 1. overall rating (Excellent-Very poor); 2. if the course was (a) easy to understand, (b) helped them to understand their health (strongly agree-strongly disagree); 3. if they would recommend the course to family and friends (yes, definitely-definitely not).

5. Shared Decision Making. A purpose-developed 14-item curriculum-based Shared Decision Making knowledge questionnaire (see Additional file 3) will cover Shared Decision Making competencies including comprehension of Shared Decision Making terms and concepts, probabilities and risk information. To assess the question asking component of the Shared Decision Making module we will ask all students to list (free-response) questions they considered important to discuss with their doctor, and code responses using content analysis. We will ask students who received the intervention to recall the AskShareKnow questions (free response), and analyse data following the method used by Shepherd et al. [37].

Six-month follow-up measures:

As assessed at baseline and immediately post intervention

1. Confidence.

2. Health Literacy Questionnaire.

3. Shared Decision Making.

a. decisional conflict using the SURE scale [49].

b. decision making preferences using the Control Preferences scale [50].

c. recall of the three AskShareKnow questions, use in health-care consultations based on self-report by participants, and comments on AskShareKnow materials (intervention only).

Additional measures

4. Health knowledge using a 12-item curriculum based measure to assess retention of core components of health knowledge. 7 items related to health information and services, and 5 items were about serve sizes. See Additional file 4.

5. Healthy lifestyle using self-report questions of daily: fruit and vegetable intake (number of serves); walking, and moderate and hard physical activity. These measures were taken from the 45 and Up Study [51].

6-12 month follow-up

1. Program retention rate: data on the proportion of adults enrolled in the program who complete the entire program, and proportion of classes attended will be collected. 
2. Enrollment in further TAFE adult education programs 12 months following course completion.

These final two endpoints will be assessed by enrolment records collected routinely by TAFE.

\section{Qualitative evaluation}

Semi-structured interviews will be carried out with a purposively selected sub-sample of students $(n=30)$ who participated in the program to examine their experiences of the program and its impact on their knowledge, understanding, confidence and capabilities. The sample will include students selected from regional and metropolitan areas and varied levels of participation (from noncompletion to full completion). Interviews will be carried out face to face and by telephone, audio recorded and transcribed verbatim. Data will be analysed thematically using Framework Analysis.

\section{Evaluation among teachers and community health workers Quantitative evaluation}

Intervention teachers will be asked to comment on and rate the teaching resources using a 5 point Likert scale (very good - very poor) with space for additional comments. This measure is included within the teaching manuals and is intended to be completed following each lesson.

\section{Qualitative evaluation}

Telephone interviews will be conducted with all intervention teachers and community health workers, and a subset of standard LLN teachers, on completion of the program. The interviews will explore their experiences and views on the content, delivery and success of the program, challenges faced, suggestions for improvement and how adult literacy teachers and health professionals worked together to deliver the program. Standard LLN teachers will be asked about experiences with the class and possibilities for contamination. As before interviews will be audio recorded, transcribed verbatim and thematically analysed.

\section{Statistical analysis}

The primary analysis will be by intention to treat. We will compare outcomes between the intervention and standard LLN arms for the primary outcome using a regression analysis that will account for clustering using appropriate methods [52]. We will use linear, logistic or ordinal logistic regression analyses as appropriate.

We will also conduct secondary analyses that adjust for baseline scores on the measures (where available), and health literacy and numeracy (measured with NVS). We will conduct these analyses separately. We will also conduct the same set of analyses for the primary outcomes, but using the intervention as actually received.

The statistician will be blinded to the allocated group definitions (i.e., health literacy vs standard LLN) until completion of the statistical analysis.

\section{Quality assurance}

Data will be collected on paper-based questionnaires and entered into a central computerised database. Ten percent $10 \%$ of records will be manually checked against the paper copies. For knowledge items that require coding and scoring, double-marking will be conducted to ensure consistency.

\section{Project reference committee}

A cross-sectoral reference group will oversee the research, comprising representatives from partner organisations (National Prescribing Service, Clinical Excellence Commission, NSW Health, TAFE NSW), the Chief/Partner Investigators, and NSW Health Literacy Network, a national group chaired by the NSW CEC involving state and national stakeholders from health, adult education, and consumer representatives; and external experts in health and adult education. The target group (i.e. adult learners with low literacy) will be represented by an appointed 'consumer representative' and by being actively involved in the development of the health literacy program to ensure the content and structure of the program is tailored to their needs, preferences and skill level.

\section{Expected outcomes of the study}

This research aims to develop and evaluate a novel adult health literacy training program to improve both language, literacy, and numeracy skills, together with specific health literacy competencies among socially disadvantaged Australian adults. It will assess the achievement of key literacy and health literacy outcomes when delivered under "real life" conditions at selected Australian adult education centres, and provide evidence on how the program can be implemented in varied circumstances. There is no existing model for collaboration in Australia between statutory adult education and public health organisations that systematically addresses both health and education outcomes. This project will enable us to test this cross-sector collaboration and provide high quality data to inform both education and health policy decisions.

\section{Discussion}

This study seeks to demonstrate effectiveness of a health literacy program embedded in an adult basic education setting, in improving both health literacy and adult education outcomes. In the process of doing so, it seeks to build partnerships between health and education agencies to 
find new ways to deliver targeted health messaging to these difficult-to-access populations. The evaluation trial will provide insight into translating and scaling up health literacy education for vulnerable populations with low literacy, including linguistically and culturally diverse adults, and durability of any observed gains. We hope that the results of this trial will influence policy makers to open pathways for health and education agencies to work together to serve the needs of these disadvantaged populations - which may reduce some of the costs to the community of limited health literacy.

\section{Registration details}

The trial is registered with the Australian New Zealand Clinical Trials Registry (registration no. ACTRN 12616000213448).

\section{Additional files}

Additional file 1: Stimuli for functional health skills measures. (PDF $430 \mathrm{~kb}$ )

Additional file 2: Scoring scheme for health skills measures. (PDF $101 \mathrm{~kb}$ )

Additional file 3: Shared decision-making (immediate follow-up).

(PDF $352 \mathrm{~kb}$ )

Additional file 4: 6 month knowledge measures (12 items). (PDF $230 \mathrm{~kb}$ )

\section{Abbreviations}

ACSF: Australian Core Skills Framework; CALD: culturally and linguistically diverse; CEC: Clinical Excellence Commission; FCE: Functional Context Education; HLQ: Health Literacy Questionnaire; LLN: language, literacy, and numeracy; NESB: non-english speaking background; NPS: National Prescribing Service; NSW: New South Wales; NVS: Newest Vital Sign; REALM: Rapid Estimate of Literacy in Medicine; SILS: Single-Item Literacy Screener; TAFE: Technical and Further Education; TOFHLA: Test of Functional Health Literacy in Adults; UK: United Kingdom; US: United States.

\section{Acknowledgements}

We would like to acknowledge Claire Wright, Patricia O'Donovan, Janelle Reece (TAFE NSW) and Chris Williams (NSW Health) for their work developing and adapting the original health literacy program; and Julie Osborne (NSW Health) for reviewing sections of the teaching manuals. We thank Karen Kaye (NPS MedicineWise) and Liz Devlin (NSW Health) for supporting the program. We would like to thank Steve Forsyth, Joy Duncan, Leonie Lagana, Sandra Lawrence, and Llewella-Sue Cobbin for helping us with the TAFE staff training and for providing logistical support to run the program. We thank Aisha Khan for her work developing the 6-month knowledge measure.

\section{Funding}

The project is funded through an Australian Research Council Linkage project grant number LP130100480. These grants support collaborations between higher education researchers (i.e. The University of Sydney) and industry partners - New South Wales (NSW) Clinical Excellence Commission, NPS MedicineWise, NSW Health and participating Institutes of TAFE NSW KM is supported by a National Health and Medical Research Council (NHMRC) career development fellowship (1029241). SS is supported by a NHMRC Early Career Fellowship (1034912).

\section{Availability of data and materials}

Not applicable.

\section{Authors' contributions}

KM, SKS, DN and KL conceived of the study and its design, with contribution from all authors (SM, DMM, HLS, HMD, AH, WM, JC). HLS, HMD and WM reviewed substantial sections of content within the teaching manuals, and SM and DM revised and adapted the manuals. AH provided guidance about data management and statistical analysis. KM, SM and DM drafted the manuscript which was read, commented on and approved by all authors (SKS, DN, KL HLS, HMD, AH, WM, JC).

\section{Competing interests}

The authors declare that they have no competing interests.

\section{Consent to publish}

Not applicable.

\section{Ethics approval and consent to participate}

The study has ethical approval from the University of Sydney and 10 NSW Institutes of TAFE. Written informed consent will be obtained from all participants.

\section{Author details}

'Sydney School of Public Health, The University of Sydney, Sydney, NSW 2006, Australia. ${ }^{2}$ Centre for Medical Psychology and Evidence-based Decision-making (CeMPED), Sydney School of Public Health, The University of Sydney, Sydney, NSW 2006, Australia. ${ }^{3}$ Psychosocial Research Group, Prince of Wales Clinical School, Faculty of Medicine, University of New South Wales, Sydney, NSW 2052, Australia. ${ }^{4}$ Psycho-oncology Co-operative Research Group (PoCoG), School of Psychology, The University of Sydney, Sydney, NSW Australia. ${ }^{5}$ Centre for Medical Psychology and Evidence-based Decision-making (CeMPED), School of Psychology, The University of Sydney, Sydney, NSW 2006, Australia. ${ }^{6}$ Concord Clinical School, The University of Sydney, Sydney, NSW 2006, Australia. ${ }^{7}$ School of Public Health and Community Medicine, University of New South Wales, Sydney, NSW 2052, Australia. ${ }^{8}$ Patient Based Care, Clinical Excellence Commission, Sydney, NSW 2000, Australia. ${ }^{9}$ NPS Medicinewise, Surry Hills, NSW 2010, Australia. ${ }^{10}$ Center for International Education, University of Massachusetts, Amherst, MA 01003, USA.

Received: 22 March 2016 Accepted: 23 April 2016

Published online: 27 May 2016

\section{References}

1. Institute of Medicine. Health literacy: a prescription to end confusion. Washington DC: National Academies Press; 2004.

2. US Department of Health and Human Services. Healthy people 2010: understanding and improving health. Washington DC: US Government Printing Office; 2000.

3. Nutbeam D. Health literacy as a public health goal: a challenge for contemporary health education and communication strategies into the 21st century. Health Promot Int. 2000;15:259-67.

4. Smith SK, Trevena L, Nutbeam D, Barratt A, McCaffery KJ. Information needs and preferences of low and high literacy consumers for decisions about colorectal cancer screenings: utilizing a linguistic model. Health Expect. 2008; 11:123-36.

5. Davis TC, Crouch MA, Long SW, Jackson RH, Bates P, George RB, Bairnsfather LE. Rapid assessment of literacy levels of adult primary care patients. Fam Med. 1991;23:433-5.

6. Parker RM, Baker DW, Williams MV, Nurss JR. The test of functional health literacy in adults: a new instrument for measuring patients' literacy skills. J Gen Intern Med. 1995;10:537-41.

7. Bennett IM, Chen J, Soroui JS, White S. The contribution of health literacy to disparities in self-rated health status and preventive health behaviors in older adults. Ann Fam Med. 2009;7:204-11.

8. Berkman ND, Sheridan SL, Donahue KE, Halpern DJ, Crotty K. Low health literacy and health outcomes: an updated systematic review. Ann Intern Med. 2011;155(2):97-107.

9. Australian Bureau of Statistics. Adult literacy and life skills survey Australia: user guide. Canberra, ACT, Australia: Australian Bureau of Statistics; 2006.

10. World Health Organisation. In: Kickbush I, Pelikan JM, Apfel F, Tsouros AD, editors. Health literacy: the solid facts. 2013.

11. Kutner M, Greenberg E, Jin Y, Paulsen C. The health literacy of America's adults: results from the 2003 National Assessment of Adult Literacy. Washington, DC: National Center for Education Statistics: U.S. Department of Education; 2006 
12. Nutbeam D, Wise M. Australia: planning for better health. Opportunities for health promotion through the development of national health goals and targets. Promot Educ. 1993;Spec No:19-24.

13. Australian Commission on Safety and Quality in Health Care. Health literacy national statement: taking action to improve safety and quality. 2014. http:// www.safetyandquality.gov.au/wp-content/uploads/2014/08/Health-LiteracyTaking-action-to-improve-safety-and-quality.pdf. Accessed 13 May 2016.

14. U.S. Department of Health and Human Services. In: Office of Disease Prevention and Health Promotion, editor. National action plan to improve health literacy. Washington, DC: U.S. Department of Health and Human Services; 2010

15. Charles C, Gafni A, Whelan T. Shared decision-making in the medical encounter: what does it mean? (or it takes at least two to tango). Soc Sci Med. 1997:44(5):681-92.

16. Hoffmann TC, Legare F, Simmons MB, McNamara K, McCaffery K, Trevena L, Hudson B, Glasziou PP, Del Mar CB. Shared decision making: what do clinicians need to know and why should they bother? Med J Aust. 2014; 201(1):35-9.

17. Patient Patient Protection and Affordable Care Act - Title I: Quality, Affordable Health Care for All Americans-Subtitle A: Immediate Improvements in Health Care Coverage for All Americans. Public Law No: 111-148(03/23/2010). Available at https://www.congress.gov/bill/111thcongress/house-bill/3590. Accessed 13 May 2016.

18. NHS England. Shared decision making. http://sdm.rightcare.nhs.uk/ NHS England; Accessed 10 Oct 2015.

19. O'Connor A, Bennett C, Stacey D, Barry M, Col N, Eden K, Entwistle V, Fiset V, Holmes-Rovner M, Khangura S, et al. Decision aids for people facing health treatment or screening decisions. Cochrane Database Syst Rev. 2009;8(3): CD001431.

20. Stacey D, Legare F, Col NF, Bennett CL, Barry MJ, Eden KB, Holmes-Rovner M, Llewellyn-Thomas H, Lyddiatt A, Thomson $R$, et al. Decision aids for people facing health treatment or screening decisions. Cochrane Database Syst Rev. 2014;1:CD001431.

21. Stewart MA. Effective physician-patient communication and health outcomes: a review. Can Med Assoc J. 1995;152:1423-33.

22. Joosten EA, DeFuentes-Merillas $L$, de Weert $G H$, Sensky $T$, van der Staak $C P$, de Jong CA. Systematic review of the effects of shared decision-making on patient satisfaction, treatment adherence and health status. Psychother Psychosom. 2008;77:219-26.

23. Shay LA, Lafata JE. Where is the evidence? A systematic review of shared decision making and patient outcomes. Med Decis Making. 2015;35:114-31.

24. McCaffery KJ, Holmes-Rovner M, Smith SK, Rovner D, Nutbeam D, Clayman ML, Kelly-Blake K, Wolf MS, Sheridan SL. Addressing health literacy in patient decision aids. BMC Med Inform Decis Mak. 2013;13 Suppl 2:S10.

25. Sholet L. Health and literacy: perspectives in 2002. Melbourne: Adult Literacy and Numeracy Australian Research Consortium, Nathan Queensland Centre; 2002.

26. Nutbeam D. The evolving concept of health literacy. Soc Sci Med. 2008;67:2072-8

27. Wickert R, McGuirk J. Integrating literacies: Using partnerships to build literacy capabilities in communities. Adelaide: National Centre for Vocational Education Research; 2005.

28. Rudd R. A maturing partnership. Focus Basics. 2002;5(C). http://www.ncsall. net/index.php@id=247.html. Accessed 13 May 2016.

29. Soricone L, Rudd R, Santos M, Capistrant B. Health literacy in adult basic education: designing lessons, units and evaluation plans for an integrated curriculum. Boston: National Center for Study of Adult Learning and Literacy; 2007.

30. Chervin C, Clift J, Woods L, Krause E, Lee K. Health literacy in adult education: a natural partnership for health equity. Health Promot Pract. 2012;13:738-46.

31. Hoeft K, Bowling M, Diehl S. Efficacy evaluation of the Expecting the Best health literacy curriculum: a pilot study. In: APHA 135th Annual Meeting and Expo 2007. Washington, DC: Adult Literacy and Numeracy Australian Research Consortium, Nathan Queensland Centre; 2007.

32. Levy S, Rasher S, Carter S, Harris L, Berbaum M, Mandernach J, et al. Health Literacy Curriculum Works forAdult Basic Education Students. Focus on Basics. 2008;9(B):33-9.

33. Soto Mas F, Ji M, Fuentes BO, Tinajero J. The Health Literacy and ESL study: a community-based intervention for Spanish-speaking adults. J Health Commun. 2015;20:369-76.
34. Tavistock Institute and Shared Intelligence. Evaluation of the second phase of the Skilled for Health programme. London: Tavistock Institute and Shared Intelligence; 2009. Available from: http://www.tavinstitute.org/projects/ report-evaluation-of-phase-two-of-the-skilled-forhealth-programme/. Accessed 13 May 2016.

35. Muscat DM, Morony S, Shepherd HL, Smith SK, Dhillon HM, Trevena L, Hayen A, Luxford K, Nutbeam D, McCaffery K. Development and field testing of a consumer shared decision-making training program for adults with low literacy. Patient Educ Couns. 2015;98:1180-8

36. Shepherd HL, Barratt A, Trevena L, McGeechan K, Carey K, Epstein RM, Butow PN, Del Mar CB, Entwistle V, Tattersall MH. Three questions that patients can ask to improve the quality of information physicians give about treatment options: a cross-over trial. Patient Educ Couns. 2011;84: 379-85.

37. Shepherd HL, Barratt A, Jones A, Bateson D, Carey K, Trevena L, McGeechan K, Del Mar CB, Butow PN, Epstein RM, Entwistle V, Weisberg E. Can consumers learn to ask three questions to improve shared decision making? A feasibility study of the ASK (AskShareKnow) Patient-Clinician Communication Model $^{\oplus}$ intervention in a primary health-care setting. Health Expectations. 2015. doi:10.1111/hex.12409.

38. McCambridge J, Witton J, Elbourne DR. Systematic review of the Hawthorne effect: new concepts are needed to study research participation effects. J Clin Epidemiol. 2014:67:267-77.

39. Sticht T. The theory behind content-based instruction. Focus on Basics. 1997;1(D). http://www.ncsall.net/index.html@id=433.html. Accessed 13 May 2016

40. Rudd RE, Rosenfeld L, Gall V. Health literacy and arthritis research and practice. Curr Opin Rheumatol. 2007;19:97-100.

41. Muscat D, Smith S, Dhillon H, Morony S, Davis EL, Luxford K, Shepherd HL, Wright C, Hayen A, Comings J, et al. Incorporating health literacy in education for socially disadvantaged adults: an Australian feasibility study. Int J Equity Health. 2016. doi:10.1186/s12939-016-0373-1.

42. Norman GR, Sloan JA, Wyrwich KW. Interpretation of changes in healthrelated quality of life: the remarkable universality of half a standard deviation. Med Care. 2003;41:582-92.

43. Morris NS, MacLean CD, Chew LD, Littenberg B. The Single Item Literacy Screener: evaluation of a brief instrument to identify limited reading ability. BMC Fam Pract. 2006;7:21.

44. Jeppesen KM, Coyle JD, Miser WF. Screening questions to predict limited health literacy: a cross-sectional study of patients with diabetes mellitus. Ann Fam Med. 2009:7:24-31.

45. Weiss BD, Mays MZ, Martz W, Castro KM, DeWalt DA, Pignone MP, Mockbee J, Hale FA. Quick assessment of literacy in primary care: the newest vital sign. Ann Fam Med. 2005;3:514-22.

46. Chew LD, Bradley KA, Boyko EJ. Brief questions to identify patients with inadequate health literacy. Fam Med. 2004;36:588-94.

47. Osborne RH, Batterham RW, Elsworth GR, Hawkins M, Buchbinder R. The grounded psychometric development and initial validation of the Health Literacy Questionnaire (HLQ). BMC Public Health. 2013;13:658.

48. Hibbard J, Mahoney E, Stockard J, Tusler M. Development and testing of a short form of the patient activation measure. Health Serv Res. 2005;40:1918-30

49. Legare F, Kearing S, Clay K, Gagnon S, D'Amours D, Rousseau M, O'Connor A. Are you SURE? Assessing patient decisional conflict with a 4-item screening test. Can Fam Physician. 2010;56:e308-14.

50. Degner LF, Sloan JA, Venkatesh P. The control preferences scale. Can J Nurs Res. 1997:29:21-43.

51. Sax Institute. Questionnaires. 2015. https://www.saxinstitute.org.au/our-work/ 45-up-study/questionnaires/: Sax Institute. Accessed 13 May 2016.

52. Hayes RJD, Moulton LH. Cluster randomised trials. Boca Raton: CRC Press; 2009 